\title{
Functional Capacity Change after Phase II Cardiac Rehabilitation as a Predictor of Major Adverse Cardiac Event in Left Ventricular Dysfunction Patients Underwent Coronary Artery Bypass Grafting
}

\author{
Hery D. Putra ${ }^{1}$, Cut Aryfa Andra ${ }^{2}$, Zainal Safri ${ }^{2}$, Andika Sitepu ${ }^{2}$, \\ Andre P. Ketaren ${ }^{2}$, Harris Hasan ${ }^{2}$ \\ ${ }^{1}$ Cardiology Resident of Cardiology Department, Faculty of Medicine, Sumatera Utara University \\ ${ }^{2}$ Cardiology Supervisor of Cardiology Department, Faculty of Medicine, Sumatera Utara University
}

Corresponding Author: Hery D. Putra

\begin{abstract}
Background: Phase II cardiac rehabilitation is essential for management post coronary artery bypass graft $(\mathrm{CABG})$, especially in patients with left ventricular systolic dysfunction. Change in functional capacity after phase II cardiac rehabilitation ( $\triangle \mathrm{METs}$ ) is an indicator of cardiopulmonary and hemodynamic improvement after CABG. This study assessed the correlation of $\triangle \mathrm{METs}$ as a predictor of major adverse cardiac event (MACE) 3 months after $\mathrm{CABG}$ in patients with left ventricular systolic dysfunction.
\end{abstract}

Methods: A cohort study was conducted on patients with left ventricular systolic dysfunction who underwent CABG between January 2019 to January 2021. Then patients were recruited to phase II cardiac rehabilitation, $\triangle$ METs was measured and tabulated by differences of functional capacity before and after the program. The abnormalities of $\triangle \mathrm{METs}$ were discovered as a predictor of MACE determined by cut-off point, which is combination of death and rehospitalization. Patients were monitored for 3 months after CABG.

Result: Among 91 patients, 24.2\% had MACE (6.6\% death and $17.6 \%$ rehospitalization). We found significant correlation between $\triangle$ METs and MACE with cut-off point 3.25 METs (p $<0.001$ ). Multivariate analysis using logistic regression showed lower $\triangle$ METs group had significant correlation with MACE (OR 0.135; $\mathrm{p}$ $0.03)$. Kaplan Meier survival analysis showed lower $\triangle \mathrm{MET}$ s group was predictor of MACE on 3 months after CABG, risk of MACE occurrence 3.9 times than higher $\triangle \mathrm{MET}$ group ( $\mathrm{p}<0.001)$.

Conclusion: Change in functional capacity could predict MACE on 3 months follow-up of left ventricular systolic dysfunction patients who underwent CABG.

Keywords: Change in functional capacity; left ventricular systolic dysfunction; MACE; CABG

\section{INTRODUCTION}

Ischemic heart disease is a major global cause of death and also a public health burden that is difficult to treat. Ischemic heart disease or coronary heart disease (CAD) is defined as a syndrome of recurrent and transient episodes of chest pain that reflects an imbalance between oxygen availability and consumption. Coronary heart disease is a cause of mortality in the United States, which is $31 \%$ of all causes of death in 2013 in the country are caused by ischemic heart disease. ${ }^{1,2}$ Coronary heart disease is the highest contributor to cardiovascular death in the world and accounts for $12.9 \%$ of total overall deaths in Indonesia as the second 
rank, after stroke as the leading cause of death. ${ }^{3,4}$

Coronary revascularization has been widely considered to improve symptoms and improve prognosis. Percutaneous coronary intervention (PCI) and coronary artery bypass surgery $(\mathrm{CABG})$ are effective and beneficial in patients with significant coronary artery disease lesions. Concrete coronary artery surgical measures are indicated to improve symptoms, prolong life, and improve quality of life. Research conducted by Esmaeeli et al, showed an improvement in functional capacity in patients undergoing coronary artery bypass surgery before and after 18 months follow up. 5,6

The main objective of the heart rehabilitation program as secondary prevention of coronary heart disease is to increase activity tolerance in patients undergoing coronary artery bypass surgery. Phase II heart rehabilitation programs can provide significant improvements in intolerance of activity and functional capacity, increase psychosocial well-being, improve symptoms that limit physical activity, reduce disability, and reduce cardiovascular morbidity and mortality. ${ }^{7,8}$

Decreased left systolic function is a predictor of mortality in IHD patients and according to the results of previous studies, cardiac rehabilitation can improve left ventricular systolic function. However, there is still little information about the effects of heart rehabilitation exercises on the left ventricular ejection fraction. Many literature reviews do not provide clear information about the uniformity of exercise and the best time to start heart rehabilitation in IHD patients. In research conducted by Haddadzadeh and colleagues, exercise programs that begin as early as possible 1 month after treatment and are carried out for 12 weeks in IHD patients can improve heart muscle contractility assessed from the left ventricular ejection fraction. ${ }^{9}$

Based on the results of previous studies, guidelines for cardiac rehabilitation exercises were issued in patients with systolic dysfunction who were clinically stable using pharmacological therapy. HFACTION trial study, showed that patients with stable systolic heart failure could undergo aerobic heart rehabilitation exercises and the procedure was safe for patients, there was even a tendency to decrease rehospitalization and mortality in these patients. ${ }^{10}$

The study aims to assess the impact and relationship between functional capacity changes after phase II cardiac rehabilitation as a predictor of major cardiovascular events (MACE) in the form of rehospitalization and mortality in 3 months in patients with left ventricular systolic dysfunction who underwent previous coronary artery bypass surgery.

\section{METHODS}

This study was a study with a cohort design that analyzed the changes in the functional capacity of the heart function before and after phase II heart rehabilitation as a predictor of major cardiovascular events and also a prognosis in patients with left ventricular systolic dysfunction who undergo coronary artery bypass surgery, where the sampling technique as an executive sampling.

The sample of this study was the patients who underwent coronary artery bypass surgery and followed by phase II cardiac rehabilitation program subsequently, at the Adam Malik General Hospital (RSUP HAM) Medan from the period January 2019 - January 2021.

The cardiac rehabilitation program was carried out for 6 weeks with 12 meetings where each training session with a duration of 30-40 minutes consists of warming up; followed by aerobic exercise consisting of 3 stages which are walking for 10 minutes, treadmill for 10 minutes, and cycling for 10 minutes; then followed by a cooling down. At the first heart rehabilitation meeting, an evaluation was conducted with 6MWT (six minutes walking test) where functional capacity was assessed in METs using formulas from 
ACSM guidelines. The intensity and duration of the exercise program are gradually increased every week according to the patient's ability and tolerance. At the end of phase II cardiac rehabilitation, an evaluation of functional capacity with 6MWT after the program was performed, then a recording of changes or differences in functional capacity was made on the study subject. Data on patients undergoing cardiac rehabilitation are further verified by the Cardiologist, especially a Consultant of Cardiac Prevention and Rehabilitation of the University of North Sumatera / Adam Malik General Hospital.

The mortality and rehospitalization due to cardiovascular events in patients consist of worsening heart failure, cardiogenic shock, arrhythmias, strokes, myocardial infarction, and revascularization were recorded in 3 months period. Evaluations and research results were obtained through telephone interviews, interviews when patients were treated in the outpatient center, and from the medical record of the patients. After all, data has been collected, data processing and data analysis were carried out to test the hypotheses that have been established.

Statistical analysis was conducted using SPSS software. Bivariate analysis was analyzed using the Chi-Square test or Fisher test for categorical variables. As for numeric variables, the T-independent or MannWhitney test is used. Bivariate analysis with Cox Regression analysis was used to define the causal association of variables with mortality and rehospitalization. All numeric data was converted into categorical data based on the cut-off value data obtained from the Receiver Operating Characteristic (ROC) curve. The odds ratio (OR) and 95\% confidence intervals $(\mathrm{CI})$ for each risk factor were obtained. Variables that have a p-value $<0.05$ will be included in the multivariate analysis.
A multivariate analysis was then carried out to find out what factors are related to bound variables and control confounding variables so that a pure relationship is obtained between one free variable and the bound variable. The Logistic Regression test was also used between categorical variables. A survival test was also carried out using the Kaplan Meier curve to see the patient's prognosis for 3 months of monitoring.

\section{RESULTS}

There was a total of 91 samples in this study which are described in Table 1. The average age of the study population was $57.45 \pm 5.26$ years, with the majority sex was male $(84.6 \%)$. From history taking, it was known that the most common risk factor for CAD was smoking (79.6\%) followed by dyslipidemia (60.4\%), hypertension (53.8\%), and diabetes $(42.9 \%)$. From the physical examination, the average systolic and diastolic blood pressure was $121.07 \pm 19.30 \mathrm{mmHg}$ and $73.43 \pm 11.15$ $\mathrm{mmHg}$. From laboratory examination, the middle value from the random blood glucose level, HDL, and LDL were 115 $\mathrm{mg} / \mathrm{dL}, \quad 38 \mathrm{mg} / \mathrm{dL}$, and $103 \mathrm{mg} / \mathrm{dL}$ respectively. From the echocardiographic examination, the median value of the left ventricular ejection fraction was $47 \%$, with a normal diastolic function assessment of $42.9 \%$, grade 1 diastolic dysfunction $31.9 \%$, grade 2 diastolic dysfunction $18.7 \%$, and grade 3 diastolic dysfunction $6.6 \%$. Therapy given to postoperative patients CABG consisted of Aspirin (97.8\%), Clopidogrel (27.5\%), ACE inhibitors (45.1\%), ARB (47.3\%), Beta-blockers (94.5\%), Statins (98.9\%), MRA (13.2\%). In the 3 months follow-up period, there were $6.6 \%$ mortality and $17.6 \%$ rehospitalization of the total 91 samples.

Table 1. Baseline characteristic in general

Table 1. Baseline characteristic in general
\begin{tabular}{|l|l|l|l|}
\hline Variable & Mean $^{\mathbf{a}}$ & Median $^{\mathbf{b}}$ & $\mathbf{n}(\%)$ \\
\hline Age & $57.45 \pm 5.26$ & & \\
\hline Sex & & & \\
\hline Male & & & $77(84.6)$ \\
\hline Female & & & $14(15.4)$ \\
\hline
\end{tabular}


Hery D. Putra et.al. Functional capacity change after phase II cardiac rehabilitation as a predictor of major adverse cardiac event in left ventricular dysfunction patients underwent coronary artery bypass grafting.

\begin{tabular}{|l|l|l|l|}
\hline \multicolumn{3}{|c|}{ Table 1 Continued... } & \\
\hline IHD Risk Factors & & & $49(53.8)$ \\
\hline Hypertension & & & $70(79.6)$ \\
\hline Smoking & & & $39(42.9)$ \\
\hline Diabetes & $121.07 \pm 19.30$ & & $55(60.4)$ \\
\hline Dyslipidaemia & $73.43 \pm 11.15$ & & \\
\hline Systolic BP & & $115(60-318)$ & \\
\hline Diastolic BP & & $38(18-68)$ & \\
\hline Random Blood Glucose & & $102(38-188)$ & \\
\hline HDL Level & & $47(35-52)$ & \\
\hline LDL Level & & & \\
\hline LVEF & & & $39(42.9)$ \\
\hline LV Diastolic Function & & & $29(31.9)$ \\
\hline Normal & & & $17(18.7)$ \\
\hline Diastolic Dysfunction Grade I & & & $6(6.6)$ \\
\hline Diastolic Dysfunction Grade II & & & \\
\hline Diastolic Dysfunction Grade III & & & $89(97.8)$ \\
\hline Therapy post CABG & & & $25(27.5)$ \\
\hline Aspirin & & & $41(45.1)$ \\
\hline Clopidogrel & & & $43(47.3)$ \\
\hline ACE inhibitor & & & $86(94.5)$ \\
\hline ARB & & & $90(98.9)$ \\
\hline Beta-blocker & & & $12(13.2)$ \\
\hline Statin & & & $40(44.0)$ \\
\hline MRA & & & $39(42.9)$ \\
\hline Diuretic & & $69(75.8)$ \\
\hline Antidiabetic & & & $16(17.6)$ \\
\hline MACE & & & \\
\hline No MACE & & & \\
\hline Mortality & & & \\
\hline Rehospitalization $:$ Kolmogorov-Smirnov $p$ normality test $>0.05($ normal distribution) \\
\hline \multicolumn{2}{|c|}{ Kolmogorov-Smirnov normality test $p<0.05($ not normally distributed $)$} \\
\hline
\end{tabular}

The median value of 6MWT distance was 260 meters before program and 500 meters after program. Based on the results of 6MWT, the median value of functional capacity before the program was 4.71 METs, and the average functional capacity after the program was $8.66 \pm 1.89$ METs, while changes of functional capacity before and after the program ( $\triangle \mathrm{METs})$ in average were $3.82 \pm 0.91$ METs. Maximum heart rate when a heart training test is carried out in a phase II heart rehabilitation program, with the median value of 121 times/minute. These data are provided in Table 2.

Table 2. Data characteristics of phase II cardiac rehabilitation program after CABG surgery

\begin{tabular}{|c|c|c|}
\hline Variable & Mean $^{\mathrm{a}}$ & Median $^{b}$ \\
\hline 6MWT pre-rehabilitation (meter) & & $260(100-450)$ \\
\hline 6MWT post-rehabilitation (meter) & & $500(200-700)$ \\
\hline Functional capacity pre-rehabilitation program (METs) & & $4.71(1.73-8.1)$ \\
\hline Functional capacity post-rehabilitation program (METs) & $8.66 \pm 1.89$ & \\
\hline Functional capacity change post-rehabilitation program ( $\triangle \mathrm{METs})$ & $3.82 \pm 0.91$ & \\
\hline Maximal heart rate during the stress test (minute) & & $121(74-151)$ \\
\hline
\end{tabular}

The Independent T-test means analysis test showed a significant difference between changes in functional capacity between subjects with MACE or without MACE (Table 3). Subjects with MACE had smaller functional capacity changes which is 2.68 METs, compared with subjects without the incidence of MACE which is 4.19 METs ( $p<0.001)$.

Table 3. Functional capacity change correlation with MACE

\begin{tabular}{l} 
Table 3. Functional capacity change correlation with MACE \\
\begin{tabular}{|l|l|l|l|}
\hline & $\begin{array}{l}\text { Mean(Standard } \\
\text { Deviation) }\end{array}$ & $\begin{array}{l}\text { p } \\
\text { value* }\end{array}$ & $\mathbf{9 5 \%}$ CI \\
\hline $\begin{array}{l}\text { MACE } \\
(\mathrm{n}=22)\end{array}$ & $2.68(0.54)$ & $<0.001$ & $\begin{array}{l}1.50 \quad(1.18- \\
1.81)\end{array}$ \\
\hline $\begin{array}{l}\text { No MACE } \\
(\mathrm{n}=69)\end{array}$ & $4.19(0.68)$ & & \\
\hline
\end{tabular} \\
\hline
\end{tabular}

ROC curve analysis shows an AUC predictor value of $94.8 \%$ with $p<0.001$ at the optimal cut-point value (cut off) change 
Hery D. Putra et.al. Functional capacity change after phase II cardiac rehabilitation as a predictor of major adverse cardiac event in left ventricular dysfunction patients underwent coronary artery bypass grafting.

in post-program functional capacity ( $\triangle$ METs) to major cardiovascular events was $\leq 3.25$ METs, with $95 \%$ sensitivity and specificity $87 \%$. Data was shown on Figure 1 and Table 4.

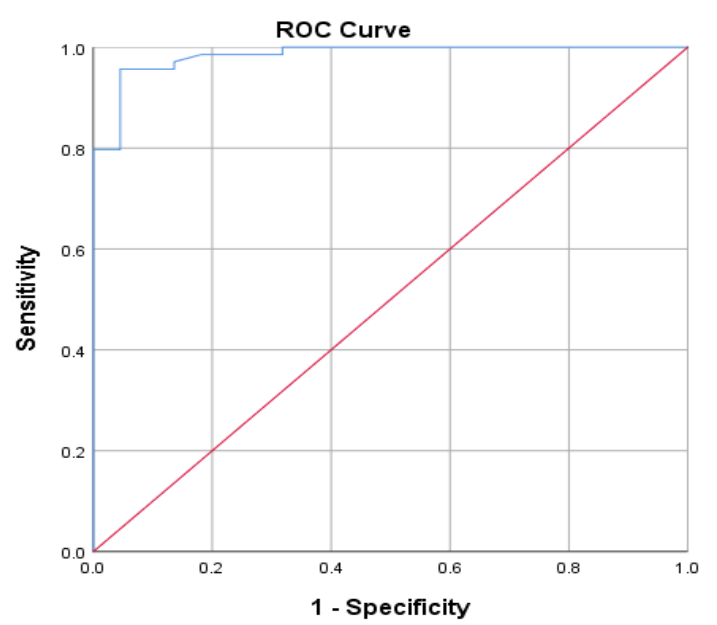

Figure 1. ROC curve of functional capacity change and MACE

Table 4. Cut off value of functional capacity change as a predictor of MACE

\begin{tabular}{|l|l|l|l|l|}
\hline $\begin{array}{l}\text { Cut-off } \\
\Delta \text { METs }\end{array}$ & Sensitivity & Specificity & AUC & p-value \\
\hline$\leq 3.25$ & $95 \%$ & $87 \%$ & 0.948 & $<0.001$ \\
\hline
\end{tabular}

Chi-square bivariate analysis showed significant differences in major cardiovascular events between the low $\triangle$ METs group and the high $\triangle$ METs group with a value of $\mathrm{p}<0.001$ (Table 5). The prevalence ratio was also acquired with the value of 3.9, meaning that the risk for major cardiovascular events in the low $\triangle \mathrm{MET}$ group is 3.9 times greater than the high $\triangle$ METs group.

Table 5. Bivariate analysis of functional capacity grouping and MACE

\begin{tabular}{|c|c|c|c|c|c|c|}
\hline & & $\overline{\mathbf{M A}}$ & & & & $\mathbf{p}^{*}$ \\
\hline & & $(+)$ & & $(-)$ & & \\
\hline & & n & $\%$ & n & $\%$ & \\
\hline ( $\triangle \mathrm{METs})$ & High & 15 & 46.9 & 17 & 53.1 & 0.001 \\
\hline & Low & 7 & 11.9 & 52 & 88.1 & \\
\hline & Total & 22 & 24.2 & 69 & 75.8 & \\
\hline
\end{tabular}

From the results of Kaplan Meier's curve analysis, it was found that patients with low $\triangle$ METs had lower survival rates than high $\triangle$ METs from the $6^{\text {th }}$ week to the $12^{\text {th }}$ week in the monitoring period (Figure 2 ). In addition, the mean survival in the low $\triangle$ METs group was the $9^{\text {th }}$ week of monitoring. During the total 3 months of monitoring, the incidence of MACE in the low $\triangle$ METs group was $46.87 \%$, while in the high $\triangle$ METs group was $11.86 \%$. The likelihood of MACE occurring in the low $\triangle$ METs group is 3.9 times higher compared to the high $\triangle$ METs group at 3 months post CABG monitoring (RR 3.9, $\mathrm{p}<0.001$ ).

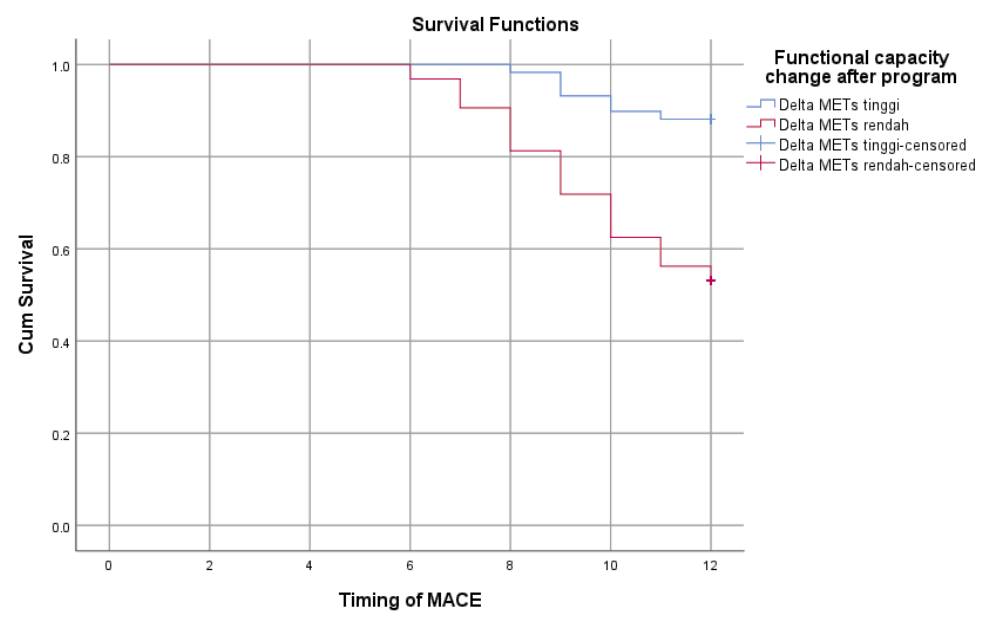

Figure 2. Kaplan Meyer survival curve of functional capacity change grouping

\section{DISCUSSION}

In this study, subjects with MACE had smaller functional capacity changes, which is 2.68 METs, compared with subjects without the incidence of MACE which is 4.19 METs $(p<0.001)$. This is in line with the review articles study conducted by Prabhu et al in 2020 that showed an increase in functional capacity after a heart rehabilitation program assessed with $6 \mathrm{MWT}$ in $\mathrm{CAD}$ patients undergoing revascularization. ${ }^{11}$ In addition, research 
conducted by Osailan \& Abdelbasset in 2019 also showed an increasing of functional capacity and hemodynamic response in post $\mathrm{CABG}$ patients underwent a heart rehabilitation program for 8 weeks assessed by incremental shuttle walking test (ISWT). The study also showed that the increasing in functional capacity after heart rehabilitation could decrease rehospitalization events. Community research by Pack et al in 2013 also concluded that post-CABG patients undergoing rehabilitation programs experienced a $46 \%$ reduction in overall cardiac death in the 10-year evaluation. ${ }^{12}$

This study also showed that cut-off point $\leq 3.25$ METs had 95\% sensitivity and specificity $87 \%$ with an AUC predictor value of $94.8 \%$ with $\mathrm{p}<0.001$ in predicting MACE. This study also showed that the likelihood of MACE occurring in the low $\triangle$ METs group was 3.9 times higher compared to the high $\triangle$ METs group at 3 months post-BPAK monitoring (RR 3.9, $\mathrm{p}$ $<0.001$ ).

Physical and aerobic exercise programs in cardiac rehabilitation can increase functional capacity without causing further complications in IHD patients. Maximum oxygen consumption (VO2 max) is the best indicator for assessing cardiorespiratory fitness levels, where high VO2 max is related to cardiovascular function, lungs, and better neurohormonal, and can reduce mortality. Heart rehabilitation programs can also increase functional capacity due to increased cardiac output and improved post CABG heart function due to improvement in ventricular filling and pumping, as well as increasing of the difference in arteriovenous oxygen content, which shows the amount of oxygen taken by the respiratory system and used optimally by the musculoskeletal system during exercise. ${ }^{8,13}$ The positive effects of physical exercise on cardiac rehabilitation include improving endothelial function and increasing nitric oxide, increasing myocardial blood flow, lowering blood pressure, and decreasing the progression of coronary artery atherosclerosis, where the overall result will improve the heart's performance and functional capacity of patients after CABG surgery. ${ }^{14}$

\section{CONCLUSION}

Changes in functional capacity before and after completing phase II cardiac rehabilitation program in coronary heart disease patients underwent coronary artery bypass surgery related to major cardiovascular events, both mortality and rehospitalization, during the 3 month postoperative evaluation. The cut off value of functional capacity change $<3.25$ METs is a predictor of overall major adverse cardiovascular events in 3 months after coronary bypass surgery, with a sensitivity of $95 \%$ and a specificity of $87 \%$. Based on survival analysis, the low functional capacity change group had a risk of major cardiovascular events 3.9 times greater than the high functional capacity change group.

Acknowledgement: None

\section{Conflict of Interest: None}

\section{Source of Funding: None}

\section{Ethical Approval: Approved}

\section{REFERENCES}

1. Ford T.J, Corcoran D, Berry C. Stable Coronary Syndromes: Pathophysiology, Diagnostic Advance and Therapeutic Need. Heart. 2018; Vol 104: 284-292.

2. Braun M.M, Stevens W.A. Stable Coronary Artery Disease: Treatment. Am Fam Physician. 2018; Vol 97(6): 376-384.

3. World Health Organization (WHO). Cardiovascular Disease. 2016; Retrieved from

URL:

https://www.who.int/cardiovascular_disease s/en

4. Health Ministry of Indonesia. Penyakit Jantung Sebagai Penyebab Kematian Tertinggi. Kementerian Kesehatan Republik Indonesia. 2017; Retrieved from URL: http://www.depkes.go.id/article/view/17073 100005/penyakitjantungpenyebabkematiant ertinggi-kemenkes-ingatkan-cerdik-.html 
Hery D. Putra et.al. Functional capacity change after phase II cardiac rehabilitation as a predictor of major adverse cardiac event in left ventricular dysfunction patients underwent coronary artery bypass grafting.

5. Faye S.R, Tsuyuki R.T, Hervas-Maloc M, et al. The influence of coronary artery bypass graft harvest site on women pain, functional status and health services utilization throughout the first post-operative year: A longitudinal study. Int. J. Nursing Stud. 2009; Vol 46: 1054-1060.

6. Esmaeeli Z, Vaezzadeh N, Tabari S.Z, et al. Quality of Life After Coronary Artery Bypass Grafting in Patients Underwent Cardiovascular Surgery in Sari / Iran. J. Mazandaran Univ. Med. Sci. 2007; Vol 17: 170-174.

7. Ades P.A. Cardiac Rehabilitation and Secondary Prevention of Coronary Heart Disease. N Engl J Med. 2001; Vol 345: 892 $-902$.

8. Lan C.L, Chen S.Y, Lai J.S. Exercise Training for Patients After Coronary Artery Bypass Grafting Surgery. In: Acute Coronary Syndrome. Rijeka, Croatia: InTech Publisher, 2006.

9. Haddadzadeh M.H, Maiya A.G, Padmakumar R, et al. Effect of ExerciseBased Cardiac rehabilitation on Ejection Fraction in Coronary Artery Disease Patients: A Randomized Controlled Trial. Heart Views. 2011; Vol 12: 51-57.

10. O'Connor C.M, Whellan D.J, Lee K.L, et $a l$. Efficacy and Safety of Exercise Training in Patients with Chronic Heart Failure: HFACTION Randomized Controlled Trial. JAMA. 2009; Vol 301(14): 1439-1450.
11. Prabhu N.V, Maiya A.G, Nivedita S.P. Impact of Cardiac Rehabilitation on Functional Capacity and Physical Activity After Coronary Revascularization: A Scientific Review. Cardiology research and Practice. 2020; Page 1-9.

12. Osailan A., Abdelbasset W.A. ExerciseBased Cardiac Rehabilitation for Post Coronary Artery Bypass Grafting and Its Effect on Hemodynamic Responses and Functional Capacity Evaluated Using Incremental Shuttle Walking Test. J Saudi Heart Assoc. 2019; DOI: https://doi.org/10.1016/j.jsha.2019.12.003

13. Van Rooy L, Coopoo Y. Comprehensive Cardiac Rehabilitation and Quality of Life in Coronary Artery Bypass Graft Patients. SA Heart. 2006; Vol. 14(3): 154-162.

14. McMahon S.R, Ades P.A, Thompson P.D. The Role of Cardiac Rehabilitation in Patients With Heart Disease. Trends Cardiovasc Med. 2017; Vol 27(6):420-425.

How to cite this article: Putra HD, Andra CA, Safri $\mathrm{Z}$ et.al. Functional capacity change after phase II cardiac rehabilitation as a predictor of major adverse cardiac event in left ventricular dysfunction patients underwent coronary artery bypass grafting. International Journal of Research and Review. 2021; 8(10): 326-332. DOI: https://doi.org/10.52403/ijrr.20211044 